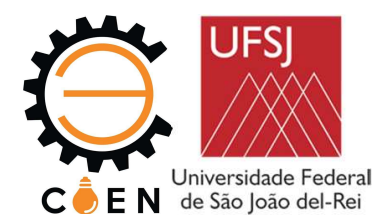

\title{
EFEITO DAS CONDIÇÕES OPERACIONAIS DE SOLDAGEM NA GEOMETRIA E ÂNGULO DE CONTATO DE UMA JUNTA SOLDADA COM ELETRODO TUBULAR AUTOPROTEGIDO
}

\author{
Gomes, B.J.C.(1) (beatrizjcgomes@gmail.com); Brites L.V.S.S. ${ }^{(1)}$ (lucasbritesufsj@hotmail.com); \\ Silva E.M. ${ }^{(1)}$ (eduardosilva@ufsj.edu.br); Brito T.G. ${ }^{(2)}$ (tgbrito@unifei.edu.br).

\footnotetext{
(1)) Universidade Federal de São João del-Rei (UFSJ); Departamento de Engenharia Mecânica
} \\ (2) Universidade Federal de Itajubá (UNIFEI- ITABIRA); Departamento de Engenharia Mecânica
}

RESUMO: Nas últimas décadas, percebe-se que o elevado crescimento tecnológico é impulsionado pelas indústrias que, para sobreviverem no mercado, são obrigadas a trabalharem sempre com parâmetros ideais e buscar a otimização dos seus processos, sendo que, na área da soldagem, isso vem ocorrendo sempre no sentido de redução do custo. Portanto, esse trabalho tem como objetivo fazer um estudo do efeito das condições operacionais de soldagem na geometria e ângulo de contato de uma junta soldada com arame tubular autoprotegido. O processo com arame tubular vem crescendo em função de sua formação de cordão com alta qualidade, bom aspecto visual e ser utilizado em todas as posições de soldagem, através de ajustes adequados de seus parâmetros operacionais. Assim, durante os experimentos, variou-se a tensão, corrente, distância bico de contato peça e velocidade de alimentação do arame. Os dados foram submetidos a análises estatísticas utilizando-se um software comercial MINITAB-14. Os resultados indicaram que as melhores regulagens dos parâmetros de soldagem são essenciais para a otimização das características geométricas do cordão. $O$ aumento da distância bico de contato peça fez o reforço diminuir e ocorrer um aumento na penetração, sendo essa condição considerada ótima para um cordão de solda.

PALAVRAS-CHAVE: Soldagem, Arame Tubular Autoprotegido, Geometria. Ângulo de contato.

\section{INTRODUÇÃO}

Nas últimas décadas, percebe-se que o elevado crescimento tecnológico é principalmente impulsionado pelas indústrias que, para sobreviverem no mercado, são obrigadas a trabalharem sempre com parâmetros ideais, levando sempre a otimização dos seus processos. Assim, a acirrada competição entre as organizações, aliada ao crescente consumo, faz com que estas busquem melhorias contínuas em seus processos e produtos. Entretanto, muitos processos de manufatura sofrem influência de um grande número de variáveis sobre suas características de qualidade e a complexidade, cada vez maior dos relacionamentos entre as saídas e as entradas de tais processos, criam barreiras que dificultam a efetiva tomada de decisão, comprometendo os níveis de eficiência e exigindo cada vez mais gestores capacitados e engajados para buscarem tomadas de decisões (PAIVA, 2008). Portanto, esse trabalho teve como início as análises realizadas pelo Brites (2018), o qual fez um estudo da influência dos parâmetros de soldagem nas características geométricas e econômicas de uma solda com arame tubular autoprotegido.

\section{REVISÃO BIBLIOGRÁFICA}

A soldagem a arco com arame tubular (FCAW) é um processo que acumula as principais vantagens da soldagem com arame maciço e proteção gasosa (GMAW), como alto fator de trabalho do soldador, alta taxa de deposição, alto rendimento e assim alta produtividade e qualidade da solda produzida. Inclui também as vantagens da soldagem manual com eletrodos revestidos (SMAW),

IX COEN - Congresso de Engenharias da UFSJ Interconexão. 

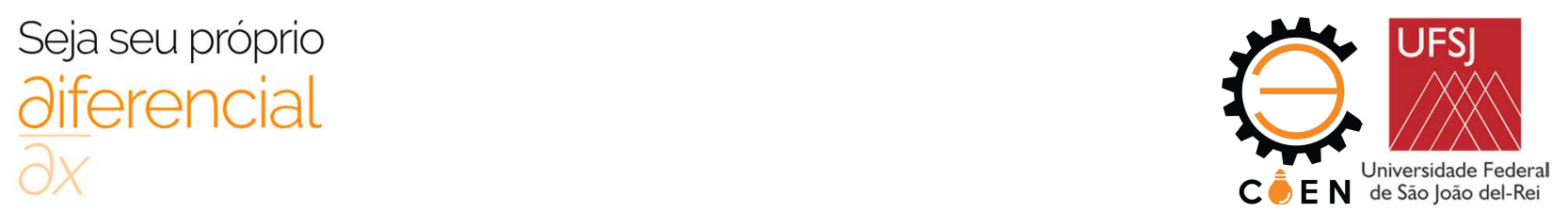

como alta versatilidade, possibilidade de ajustes da composição química do cordão de solda e facilidade de operação em campo (AWS, 1991; Marques et al, 2005). Portanto, nota-se que a soldagem com arame tubular, com ou sem proteção gasosa, pode ser um processo semiautomático, onde o soldador controla a posição e o deslocamento da tocha, ou automático, quando a tocha é deslocada pela máquina (BARNES, 2009).

Segundo Joaquim (2006), na soldagem por arame tubular com proteção gasosa, apesar da queima e vaporização do revestimento estabilizarem o arco elétrico, a pouca quantidade de revestimento não permite obter o volume necessário de gases para proteção global do banho de fusão, sendo necessário utilizar uma proteção adicional de gás, podendo ser inerte (argônio, hélio), ativo (dióxido de carbono) ou mesmo a mistura destes.

Na soldagem com arame tubular autoprotegido, o metal fundido é protegido por uma camada de escória, pelos gases e pelos elementos desoxidantes/desnitretantes ( $\mathrm{Mn}, \mathrm{Al}, \mathrm{Ti}, \mathrm{Si}, \mathrm{Mg}$, etc.), que são resultantes da decomposição do fluxo. Assim, nota-se um grande interesse em consequência da sua versatilidade e possibilidade de aplicação em ambientes sujeitos a intempéries como, na fabricação de plataformas de prospecção de petróleo, estaleiros navais, locais de difícil acesso e condições de trabalho, onde até então era absoluto o domínio do processo de soldagem por eletrodos revestidos (JOAQUIM, 2006).

Apesar da similaridade entre o processo de eletrodo tubular com proteção gasosa e o processo com arame sólido MIG/MAG, o processo com arame tubular apresenta vantagens em relação a outros processos com proteção gasosa, como alta taxa de deposição e grande rendimento, o que resulta em boa produtividade e qualidade da solda. Além disso, a soldagem apresenta melhor estabilidade do arco (BARBEDO, 2011). Assim, com o crescimento da utilização do processo de eletrodo tubular, torna-se necessário compreender as nuances das variáveis do processo para permitir uma melhor utilização do mesmo, principalmente quando comparado ao processo MIG/ MAG, bem como avaliar todos os parâmetros que são capazes de alterar o desempenho operacional do processo (GARCIA E SCOTTI, 2011).

Portanto, nota-se que vários trabalhos estão sendo publicados na literatura como Silva (2006), Starling et al (2011) e Brites (2018), porém, o estudo do processo de soldagem com eletrodo tubular autoprotegido e o comportamento desse processo é algo que ainda desperta o interesse do mundo científico, principalmente em investigar as correlações entre as variáveis do processo no sentido de buscar uma otimização dos parâmetros para aumentar a qualidade e a produtividades das juntas soldadas.

Assim, esse trabalho tem como objetivo um estudo do efeito das condições operacionais de soldagem na geometria e ângulo de contato de uma junta soldada com eletrodo tubular autoprotegido, Além disso, a verificação da variação da distância bico de contato peça e o efeito do ângulo de contato passa a ser um estudo inovador para o processo com arame tubular autoprotegido. Porém, a estabilidade operacional de cada uma das condições testadas não foram avaliadas através das análises dos oscilogramas de tensão do arco e corrente de soldagem (em particular da relação entre o desvio padrão e a média destes parâmetros, que indicam os seus níveis de flutuação durante a operação de soldagem), do aspecto superficial do cordão, do nível de respingos produzidos e da eficiência de deposição, devido à falta de um equipamento adequado para o monitoramento da soldagem. 


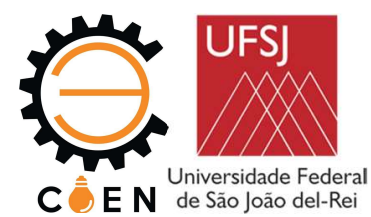

\subsection{Características do cordão de solda}

Segundo Fortes (2005), algumas características importantes do cordão de solda são sua altura ou reforço (R), largura (L) e penetração $(\mathrm{P})$ e estas podem ser observadas conforme Figura 1. Essas características são importantes para garantir que a junta de solda seja adequadamente preenchida, com um mínimo de defeitos, particularmente em soldas multipasses onde, se a altura do cordão de solda for muito grande, torna-se muito difícil depositar os passes de solda subsequentes com boa fusão. Quanto mais protuberante e estreito for o cordão de solda, maior a probabilidade de ocorrer falta de fusão, sendo interessante alterar suas características como tamanho e/ou sua forma para obter bons resultados. A corrente e a velocidade de soldagem são os parâmetros mais influentes no controle do tamanho do cordão de solda.

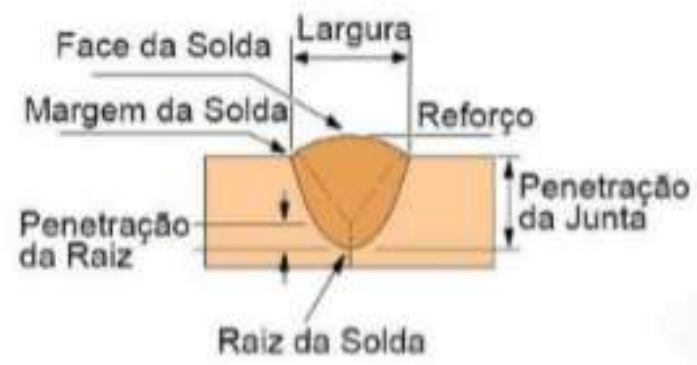

Figura 1: Parâmetros geométricos medidos no cordão. Fonte: Marques et al, 2011.

\section{2 Índice de convexidade (IC)}

O índice de convexidade é dado pela relação entre o reforço (R) e a largura (L) do cordão de solda. Os valores de R e L são aferidos no cordão como indicado na Figura 1 e são calculados através da Equação 1.

$$
I C=\frac{R}{L} x 100(\%)
$$

Segundo Bonanni (2005), é por este índice que obtemos informações importantes a respeito da qualidade do cordão, sendo possível prever se a solda apresenta reforço excessivo ou não.

\subsection{Influência da distância bico de contato}

A extensão do eletrodo (stick-out) é a distância entre o último ponto de contato elétrico, normalmente a extremidade do bico de contato, e a peça de trabalho. A Figura 2 mostra esquematicamente a extensão do eletrodo, sendo nessa região que ocorre o efeito Joule $\left(I^{2} R\right)$. 


\section{Seja seu próprio
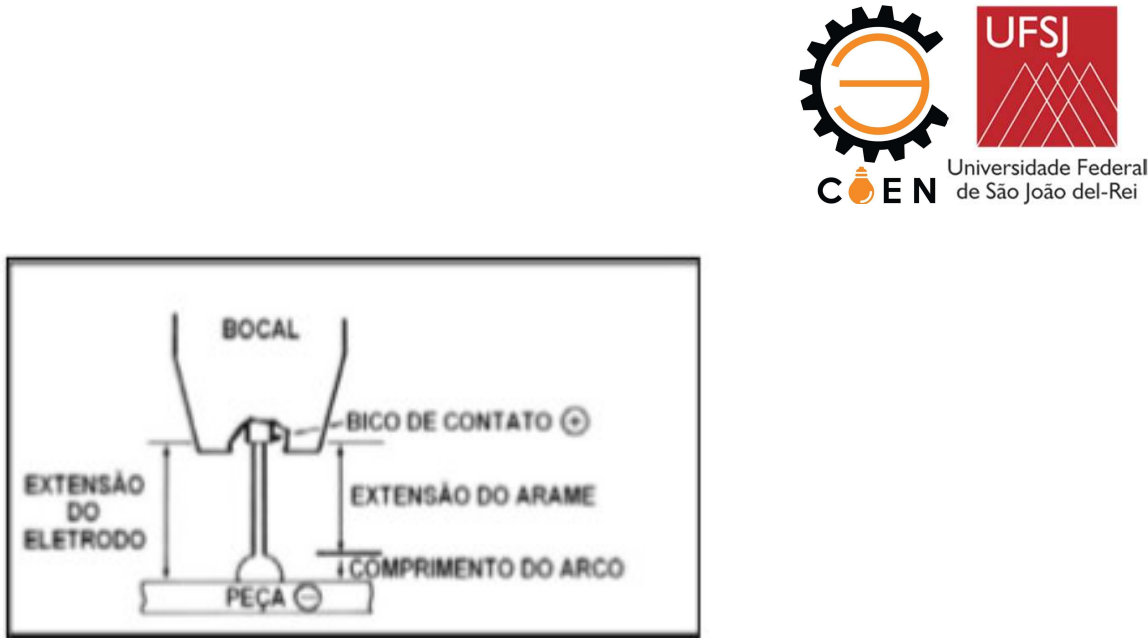

Figura 2. Distância entre o bico de contato e a peça. Fonte: Fortes, 2005.

Assim, a distância entre o bico de contato e a peça (extensão do eletrodo) afeta a corrente de soldagem necessária para fundir o arame a uma dada velocidade de alimentação de arame. Basicamente, quando essa distância é aumentada, o aquecimento devido ao efeito Joule aumenta e a corrente de soldagem necessária para fundir o arame é diminuída e vice-versa. Grandes extensões de eletrodo resultam em excesso de metal de solda sendo depositado com baixo calor do arco. Isso pode causar geometria desfavorável do cordão e baixa penetração (FORTES, 2005).

\subsection{Influência do ângulo de molhabilidade}

A molhabilidade é definida como a tendência de um líquido se espalhar na superfície de um substrato sólido, avaliada através do ângulo de contato entre o liquido e o sólido, como mostra a Figura 3. Quanto maior a molhabilidade do fluido, maior será a taxa de resfriamento durante o processo de têmpera (OTERO, 2014).
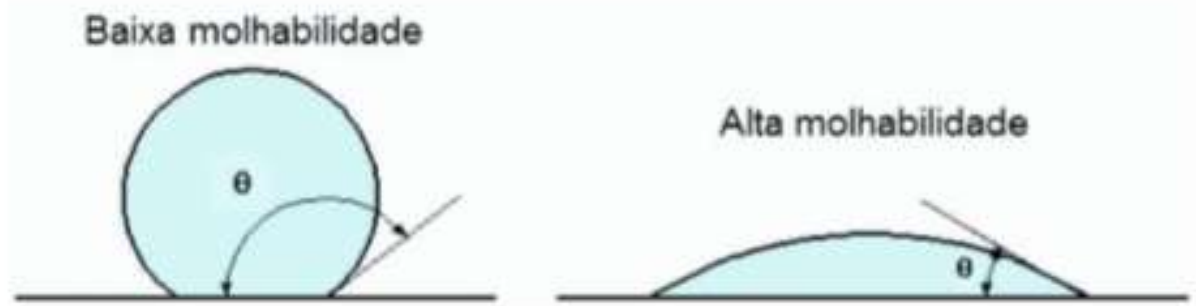

Figura 3. Comparação do ângulo de contato e a molhabilidade. Fonte: Otero, 2014.

O ângulo de molhabilidade ou ângulo de contato tem influência significativa na qualidade do revestimento de uma junta soldada em função do efeito da sobreposição do cordão. Assim, os ajustes dos parâmetros de soldagem podem melhorar a molhabilidade (fluidez) da poça de fusão, diminuindo a tensão superficial do metal fundido e reduzindo o número de defeitos (SILVA et al, 2017). Portanto, quanto maior o aumento do ângulo de molhabilidade, maior o reforço do cordão, levando a um aumento no fator de concentração de tensão e consequentemente a um aumento de tensões residuais presentes em um corpo, sem que haja forças externas ou diferença de temperatura. Logo, valores de tensões maiores que o limite de escoamento do material provocará uma deformação plástica do material, para que dessa forma as tensões sejam distribuídas (NUNES, 2016; LEMOS, 2012). 


\section{MATERIAIS E MÉTODOS}

A sequência de testes deste trabalho teve início através dos corpos de prova fabricados por Brites (2018), o qual utilizou-se do aço AISI 1020 para realizar a soldagem em 12 corpos de prova com arame tubular autoprotegido variando os parâmetros de entrada (corrente - I, tensão - V, DBCP e Va) para cada soldagem realizada.

Para avaliar a qualidade visual do cordão de solda e suas características dimensionais, primeiramente as amostras foram lixadas e polidas e atacados com nital $2 \%$. Posteriormente, essas amostras foram levadas a um projetor de perfil com aumento de $20 \mathrm{X}$, para determinar as características geométricas do cordão. A Tabela 1 mostra os fatores estudados bem como as respostas analisadas.

Tabela 1. Matriz de experimentação e resultados obtidos. Fonte: Próprio autor.

\begin{tabular}{|c|c|c|c|c|c|c|c|c|c|}
\hline \multicolumn{5}{|c|}{ Fatores de controle } & \multicolumn{5}{|c|}{ Variáveis de saída } \\
\hline Testes & $\begin{array}{c}\text { I } \\
\text { (A) }\end{array}$ & $\begin{array}{c}\text { V } \\
\text { (Volt) }\end{array}$ & $\begin{array}{l}\text { DBCP } \\
(\mathrm{mm})\end{array}$ & $\begin{array}{c}\text { Va } \\
(\mathbf{m} / \mathbf{m i n})\end{array}$ & $\begin{array}{c}\text { L } \\
(\mathbf{m m})\end{array}$ & $\begin{array}{c}\mathbf{R} \\
(\mathbf{m m})\end{array}$ & $\begin{array}{c}\mathrm{P} \\
(\mathrm{mm})\end{array}$ & $\begin{array}{l}\text { IC } \\
(\%)\end{array}$ & $\begin{array}{l}\theta \\
\left({ }^{\circ}\right)\end{array}$ \\
\hline 1 & 95 & 19 & 3 & 5,5 & 3,774 & 1,581 & 0,523 & 41,9 & 61,185 \\
\hline 2 & 95 & 19 & 3 & 6 & 3,668 & 1,90 & 0,849 & 51,9 & 63,948 \\
\hline 3 & 120 & 20 & 3 & 5,5 & 4,363 & 1,584 & 0,481 & 36,3 & 50,797 \\
\hline 4 & 120 & 20 & 3 & 6 & 5,325 & 2,417 & 0,921 & 45,4 & 68,649 \\
\hline 5 & 130 & 22 & 9 & 5,5 & 4,140 & 1,211 & 1,018 & 29,3 & 39,943 \\
\hline 6 & 130 & 22 & 9 & 6 & 4,360 & 1,884 & 0,791 & 43,2 & 56,295 \\
\hline 7 & 140 & 23 & 9 & 5,5 & 4,054 & 0,904 & 0,786 & 22,3 & 46,459 \\
\hline 8 & 140 & 23 & 9 & 6 & 4,729 & 1,729 & 1,177 & 36,6 & 53,625 \\
\hline 9 & 160 & 24 & 12 & 5,5 & 3,862 & 0,896 & 0,904 & 23,2 & 54,612 \\
\hline 10 & 160 & 24 & 12 & 6 & 3,793 & 0,831 & 1,102 & 21,9 & 41,722 \\
\hline 11 & 176 & 25 & 12 & 5,5 & 4,496 & 1,404 & 1,123 & 31,2 & 44,103 \\
\hline 12 & 176 & 25 & 12 & 6 & 4,497 & 1,400 & 1,123 & 31,2 & 46,82 \\
\hline
\end{tabular}

\section{RESULTADOS E DISCUSSÕES}

Para avaliar de maneira mais consistente os efeitos dos fatores empregados sobre as respostas observadas, utilizou-se neste trabalho o software comercial Minitab versão 14 e foram processadas todas as análises estatísticas dos ensaios, sendo os parâmetros mantidos conforme a matriz de experimentação, Tabela 1. Logo, as respostas foram submetidas a análise de variância de modo que fosse possível avaliar os efeitos das variáveis de entrada sobre as respostas analisadas, assim foi adotado um fator de confiabilidade de $95 \%$, adotando como nível de significância a 5\%. A Tabela 2 apresenta os resultados dessa análise. Observa-se que os modelos desenvolvidos são adequados, pois 


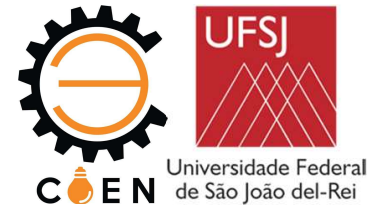

o P-value é inferior a 5\% e nota-se também que o R2(adj) está acima de 94,69\%, ou seja, o modelo desenvolvido tem um bom ajuste.

Tabela 2. Análise de Variância para as respostas L, R, P, IC(\%). Fonte: Próprio autor.

\begin{tabular}{rccccc}
\hline Força & DF & SS & MS & F & P \\
\hline Fator & 3 & 108,492 & 36,164 & 280,22 & 0,000 \\
Erro & 44 & 5,678 & 0,129 & & \\
Total & 47 & 114,170 & & & \\
$\mathbf{R}^{2}$ (adj) & & & & & 94,69 \\
\hline
\end{tabular}

\subsection{Análise de molhabilidade ou ângulo de contato}

A molhabilidade dos cordões pode ser avaliada qualitativamente através do ângulo de molhabilidade ou de contato $(\theta)$ formado entre e superfície sólida e o plano tangencial à superfície do cordão depositado. Se $\theta<90^{\circ}$, o líquido tem tendência a molhar a superfície e o oposto ocorre para $\theta>90^{\circ}$. Portanto, quanto menor este ângulo, melhor será o molhamento.

Ao avaliar a Figura 4, que demonstra o teste de normalidade efetuado com os resíduos das respostas do experimento considerando-se um nível de significância $\alpha=0,05$ e o valor do P-Value de 0,6590 , conclui-se que os resíduos seguem uma distribuição normal, o que indica que as respostas analisadas são confiáveis.

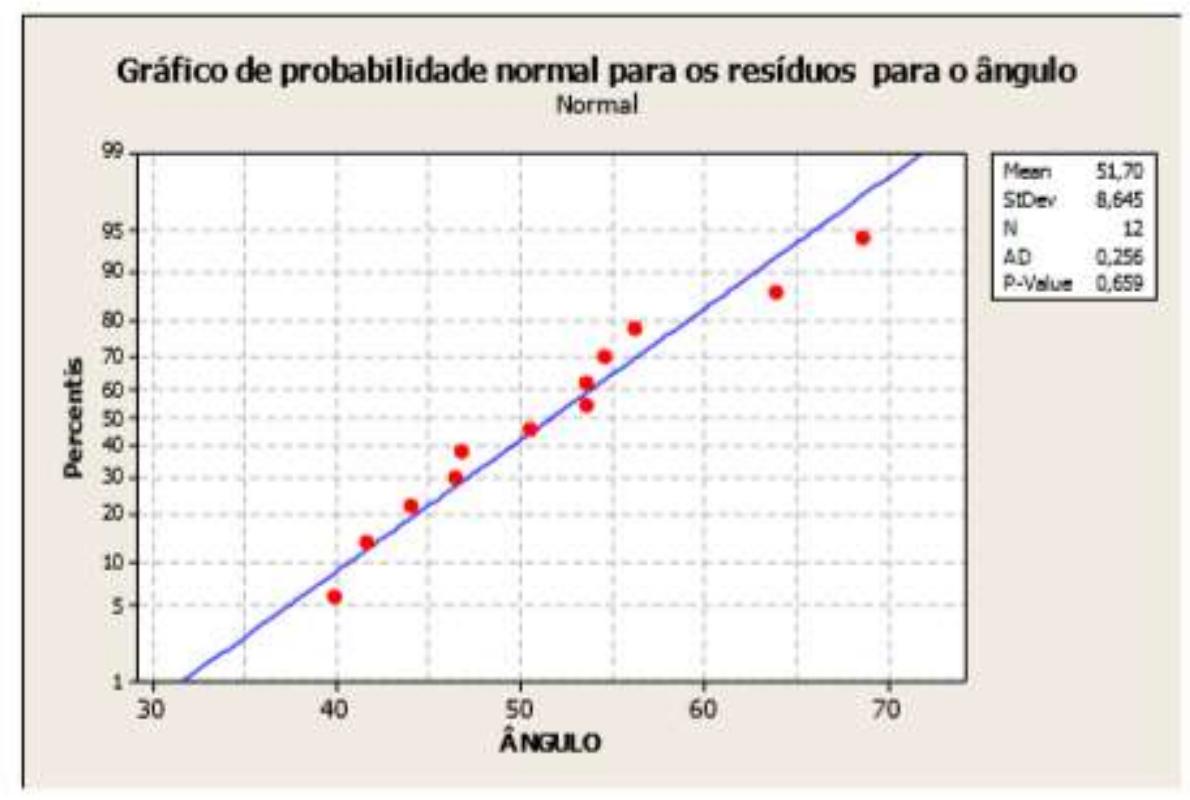

Figura 4. Probabilidade Normal dos resíduos do ângulo de contato. Fonte: Próprio autor.

A Figura 5 apresenta o gráfico dos resíduos padronizados versus a ordem padrão, assim não se percebe padrões de não aleatoriedade, a qual confronta os resíduos padronizados com a ordem dos experimentos, o que indica que o experimento foi conduzido de maneira apropriada.

IX COEN - Congresso de Engenharias da UFSJ Interconexão. 

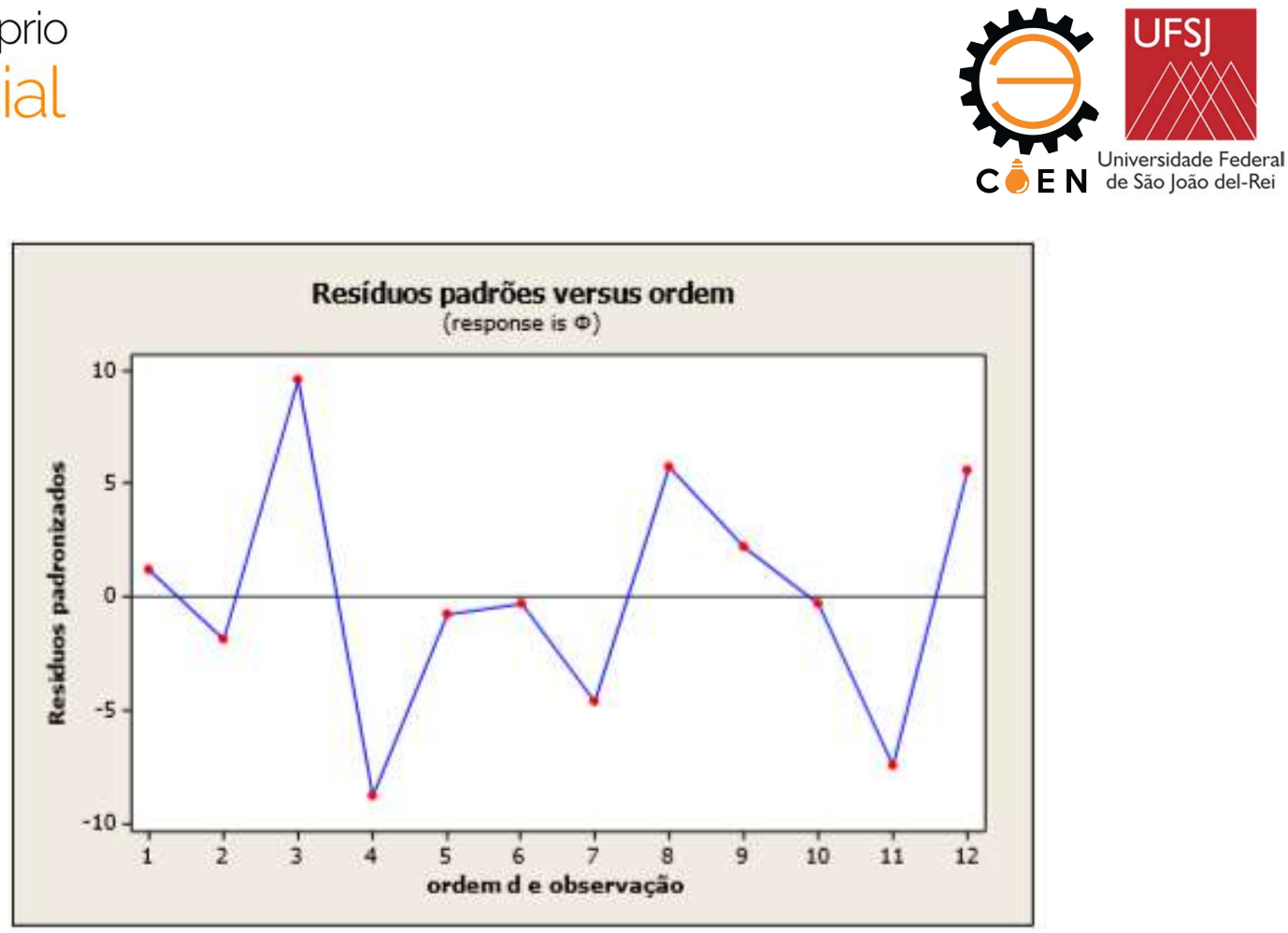

Figura 5. Gráfico dos resíduos padronizados versus a ordem padrão. Fonte: Próprio autor.

A figura 6 mostra os efeitos dos parâmetros principais sobre o ângulo de contato do cordão. Logo, nota-se que, quanto maior a corrente de soldagem, menor será o ângulo de contato do cordão, apresentando um comportamento inversamente proporcional, onde o mesmo "sentimento" ocorre para as variáveis tensão e corrente de soldagem. Portanto, através dos testes, nota-se que o ângulo de contato variou de 39,39. Ao avaliar a distância bico de contato peça (DBCP) e o ângulo de contato $(\theta)$, nota-se que quanto maior a $\mathrm{DBCP}$, menor será o ângulo de contato.

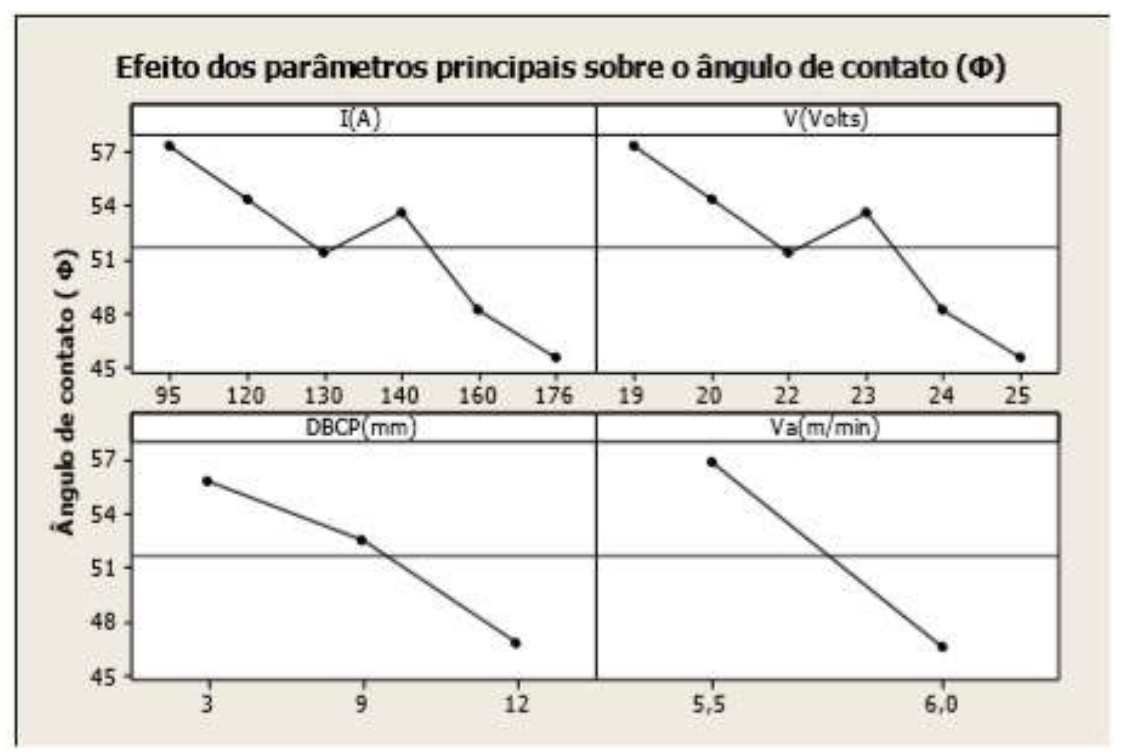

Figura 6. Efeito dos parâmetros principais sobre o ângulo de contato $(\theta)$. Fonte: Próprio autor.

IX COEN - Congresso de Engenharias da UFSJ Interconexão. 


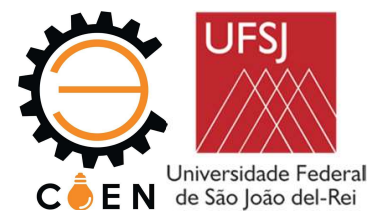

\subsection{Análise do índice de convexidade do cordão}

A convexidade do cordão de solda é um parâmetro que está ligado à qualidade do cordão, sendo este adimensional e dado pela relação entre o reforço da solda e a largura do cordão. Nota-se que o índice de convexidade (IC), quando positivo, expressa a convexidade e, quando negativo, a concavidade do cordão de solda

Ao avaliar o gráfico que demonstra o teste de normalidade efetuado com os resíduos das respostas do experimento, considerando-se um nível de significância $\alpha=0,05$ e o valor do P-Value de 0,6890, conclui-se que os resíduos seguem uma distribuição normal, o que indica que as respostas analisadas são confiáveis como indicado na Figura 7.

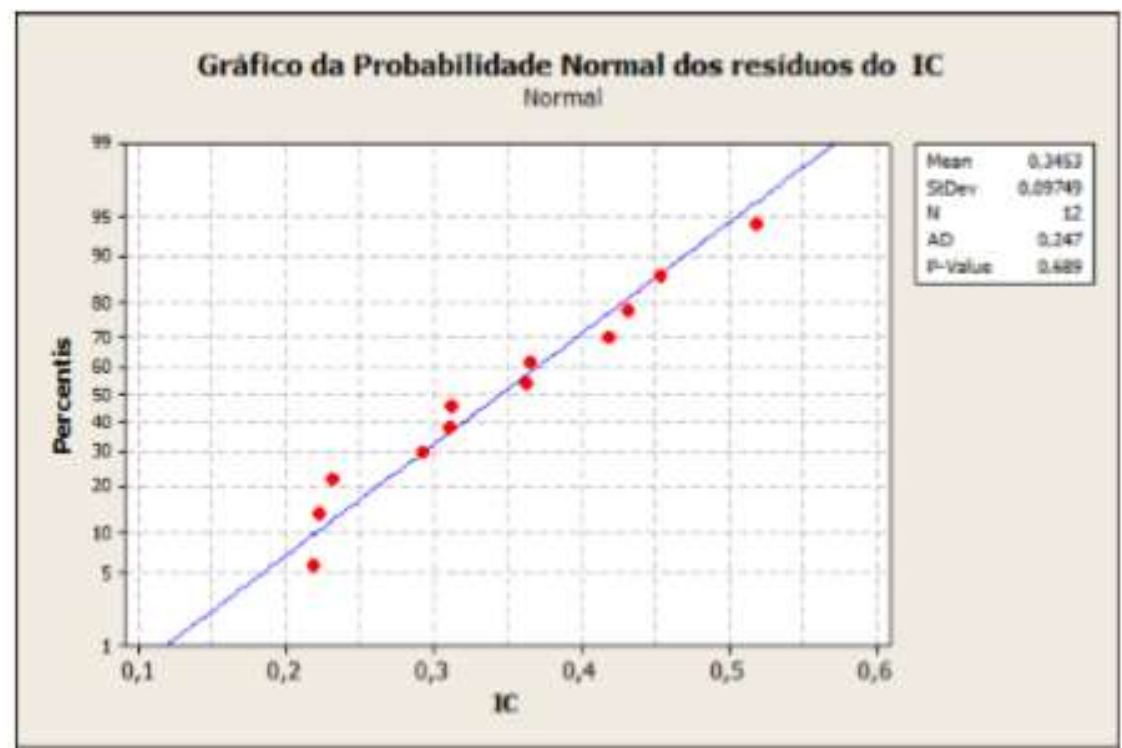

Figura 7. Probabilidade normal dos resíduos do IC. Fonte: Próprio autor

A Figura 8 apresenta o gráfico dos resíduos padronizados versus a ordem padrão, assim não se percebe padrões de não aleatoriedade na figura a qual confronta os resíduos padronizados com a ordem dos experimentos, o que indica que o experimento foi conduzido de uma maneira apropriada. 

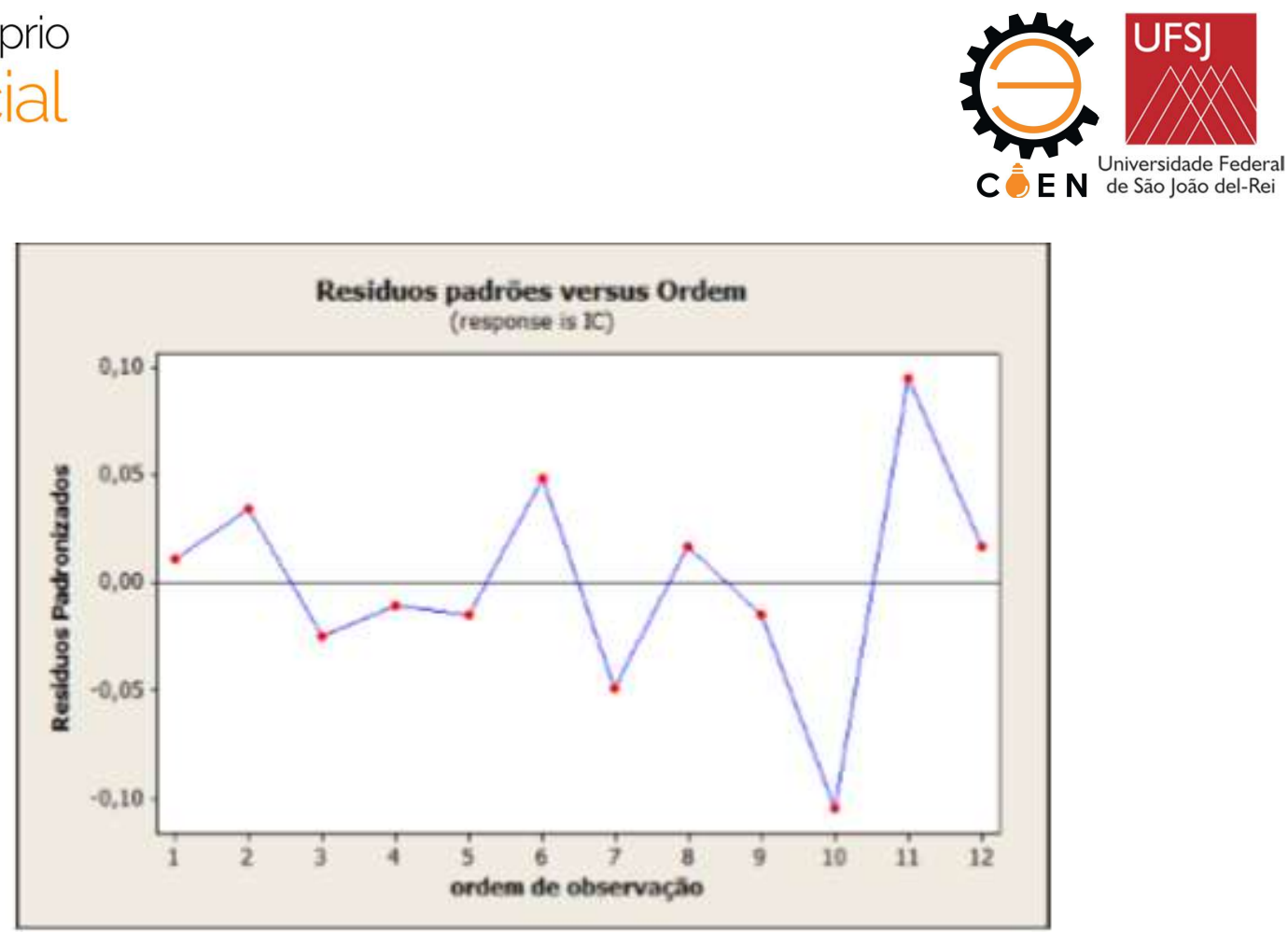

Figura 8. Gráfico dos resíduos padronizados versus a ordem padrão. Fonte: Próprio autor

A Figura 9 mostra os efeitos dos parâmetros principais sobre o índice de convexidade do cordão, sendo que, quanto menor a corrente de soldagem maior será o índice de convexidade do cordão, ou seja, percebe-se que essas variáveis tem comportamento inversamente proporcional, onde o mesmo ocorre para as variáveis tensão e corrente de soldagem. Ao avaliar a DBCP e o IC nota-se que quanto maior a DBCP menor será o IC.

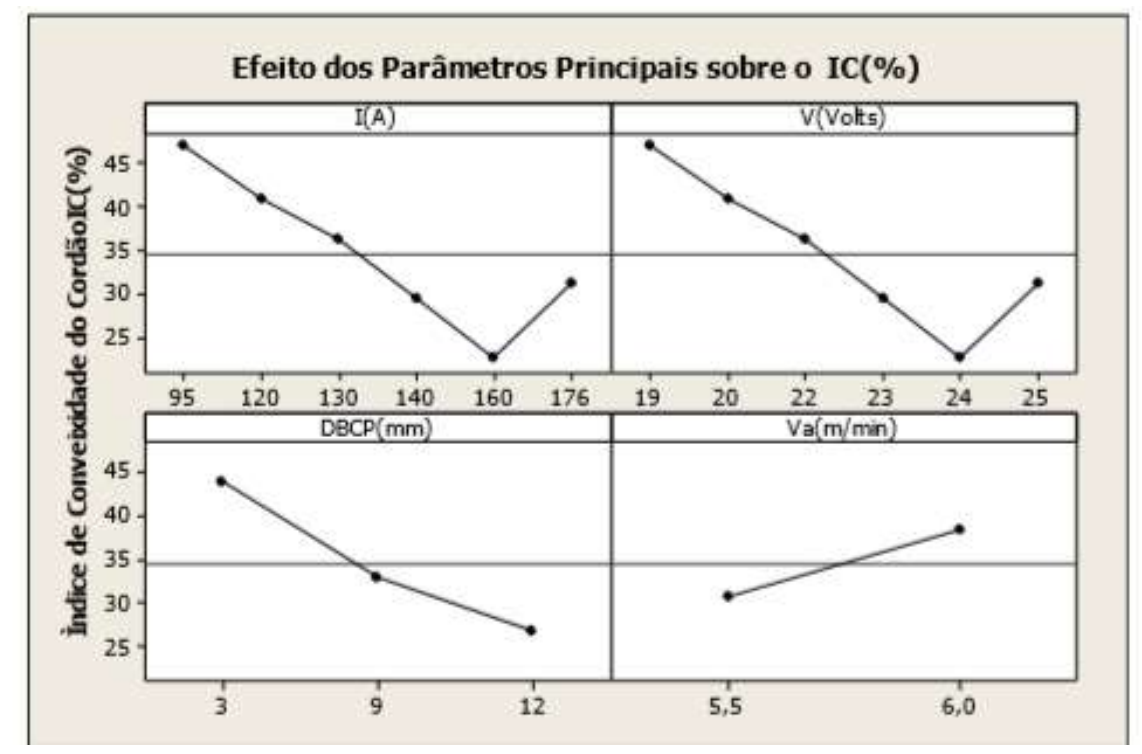

FIGURA 9. Gráfico dos Efeitos dos Parâmetros Principais sobre o Índice de Convexidade do Cordão (IC). Fonte: próprio autor

Um cordão com uma convexidade inadequada pode ocorrer por causa de defeitos na solda. Caso a convexidade seja excessiva, pode representar um concentrador de tensões facilitando o 


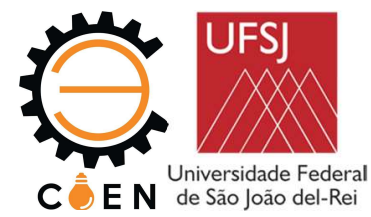

aparecimento de trincas e quando muito pequena, muitas vezes também é considerada inadequada, pois pode aparecer mordedura no cordão de solda levando a um ponto de concentração de tensão e até mesmo o surgimento de trincas. O valor do IC inferior a 30\% é considerado aceitável para este índice. Assim, analisando os testes de soldagem percebe-se que o índice de convexidade para os testes variou de 22,30 a $51,90 \%$, ou seja, os melhores ajustes para esse índice ocorrerão com maiores correntes de soldagem, aproximadamente sendo: $\mathrm{I}-176^{\mathrm{a}}, \mathrm{V}=25 \mathrm{Volts}, \mathrm{DBCP}=12 \mathrm{~mm}$ e Va=6m/min.

\section{CONCLUSÃO}

Esse trabalho, nos permite concluir, através dos resultados obtidos, que:

- A distância bico de contato peça tem uma forte influência nas características geométricas do cordão e existe uma correlação negativa entre a distância bico de contato e o índice de convexidade;

- O índice de convexidade do cordão é fortemente influenciado pelas condições operacionais de soldagem como a corrente, tensão, distância bico de contato peça e velocidade de alimentação do arame;

- As melhores condições operacionais para a soldagem com arame tubular para a resposta índice de convexidade do cordão e ângulo de contato ocorre com maiores correntes de soldagem, sendo $\mathrm{I}=176 \mathrm{~A}$ e $\mathrm{V}=25 \mathrm{Volts}, \mathrm{DBCP}=12 \mathrm{~mm}$ e $\mathrm{Va}=6 \mathrm{~m} / \mathrm{min}$;

- O ângulo de contato é fortemente influenciado pelos parâmetros operacionais da soldagem, ou seja, o menor ângulo de contato ocorre com o aumento da corrente de soldagem, tensão, distância bico de contato peça e a velocidade de alimentação do arame.

\section{DIREITOS AUTORAIS}

Os autores são os únicos responsáveis pelo conteúdo das informações contidas neste artigo.

\section{REFERÊNCIAS}

AMERICAN WELDING SOCIETY. Welding Process. In: AMERICAN WELDING SOCIETY. Welding Handbook, v.2, 8th ed., Miami: AWS, 158-190p., 1991.

BARBEDO, N. D. D. Avaliação Comparativa dos Processos de Soldagem GMAW e FCAW Utilizando Aço ASTM A-36 para Verificar a Soldabilidade, Propriedades Metalúrgicas e Geométricas e Resistência Mecânica. Dissertação de Mestrado. Universidade Federal de Itajubá. Outubro, 2011.

BARNES, G. C. Flux Cored Arc Welding. 2009.

BONANNI, C. G. Uso Combinado das Técnicas DOE e Simulação de Monte Carlo em um Processo de Soldagem MIG/MAG Pulsado. Tese de Mestrado em Engenharia de Produção. Universidade Federal de Itajubá. Itajubá, 104p., 2005. 

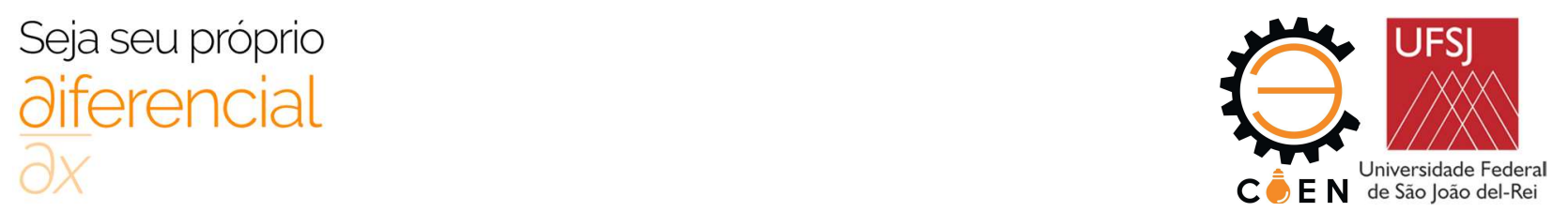

BRITES, L.V. S. S.; SILVA, E. M.; BRITO, T. G.; Influência dos Parâmetros de Soldagem nas Características Geométricas e Econômicas de uma Solda com Arame Tubular Autoprotegido. VIII- COEN - Congresso de Engenharias, UFSJ. São João Del Rei, 2018.

FORTES, C. Apostila de Soldagem MIG/MAG. ESAB. 68p., 2005.

GARCIA R.P.; SCOTTI, A. Uma Metodologia para Análises Comparativas da Capacidade Produtiva entre Arames Maciços (MIG/MAG) e Tubulares (Eletrodo Tubular). Soldagem e Inspeção. (Impr.) vol.16, no.2. São Paulo, 1-10p., 2011.

JOAQUIM, R. Processo de Soldagem por Arame Tubular. Infosolda, 1-23p., 2006.

LEMOS, G. V. B. Análise de Tensões Residuais em Eixos Automotivos do Aço DIN 38B3 Temperados por Indução. Dissertação de Mestrado em Engenharia. Universidade Federal do Rio Grande do Sul. Porto Alegre, 2012.

MARQUES, P. V., MODENESI, P. J., BRACARENSE, A. Q. Soldagem - Fundamentos e Tecnologia. $3^{\text {a }}$ ed, Editora UFMG. Belo Horizonte, 2011.

MARQUES, P. V.; MODENESI, P. J.; BRACARENSE, A. Q. Soldagem MIG/MAG e com Arame Tubular. In: MARQUES, P. V.; MODENESI, P. J.; BRACARENSE, A. Q. Soldagem: Fundamentos e Tecnologia. 1st ed. UFMG. Belo Horizonte, 233-261p., 2005.

NUNES, M. M. Utilização da Técnica de Projeto e Análise de Experimentos - Doe para o Estudo da Influência do Tratamento Térmico de Têmpera na Microestrutura do Aço ABNT 4340. TFG- Universidade Federal de Itajubá - Campus Itabira, 32p., 2016.

OTERO, R L. S. Potencialidade do uso de Formulações de Óleo de Soja Epoxidado e Éster Metílico de Ácido Graxo como Fluidos de Resfriamento no Tratamento Térmico de Têmpera de Aços. $252 \mathrm{f}$. Tese de Doutorado em Ciência e Engenharia de Materiais. Escola de Engenharia de São Carlos, Universidade de São Paulo. São Carlos, 2014.

PAIVA, E. J. Otimização de Processos de Manufatura com Múltiplas Respostas baseada em Índices de Capacidade. Dissertação de Mestrado. UNIFEI, 118p., 2008.

SILVA, F. G.; BRAGA, E. M.; FERRARESI, V. A. Adequação do Processo de Soldagem MIG/MAG com Adição de Arame Frio na Qualidade do Revestimento com Aço Inoxidável Austenítico sobre um Aço ao Carbono. $21^{\circ}$ Posmec - Simpósio do Programa de Pós- Graduação da Universidade Federal de Uberlândia, 2017.

SILVA, E. M. Comparação de Características Operacionais no Processo com Eletrodo Tubular utilizando as Transferências por Curto-Circuito e Pulsado na Posição Vertical Descendente. Dissertação de Mestrado. Universidade Federal de Itajubá, UNIFEI, 109p., 2006.

STARLING, C. M. D.; MODENESI, P. J.; BORBA, T. M. D. Caracterização do Cordão na Soldagem FCAW com um Arame Tubular "Metal Cored”. Soldag. insp. Vol. 16, No3. São Paulo, 285-300p., 2011.

IX COEN - Congresso de Engenharias da UFSJ Interconexão. 


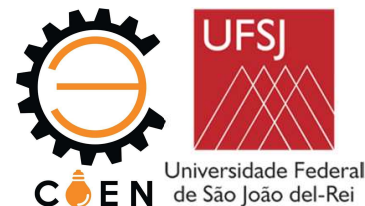

\section{EFFECT OF OPERATING WELDING CONDITIONS IN THE GEOMETRY AND CONTACT ANGLE OF A WELDED JOINT WITH SELF-PROTECTED TUBULAR ELECTRODE}

Gomes, B.J.C. ${ }^{(1)}$ (beatrizjcgomes@gmail.com); Brites L.V.S.S. ${ }^{(1)}$ (lucasbritesufsj@hotmail.com); Silva E.M. ${ }^{(1)}$ (eduardosilva@ufsj.edu.br); Brito T.G. ${ }^{(2)}$ (tgbrito@unifei.edu.br).

\footnotetext{
(1)) Universidade Federal de São João del-Rei (UFSJ); Departamento de Engenharia Mecânica

(2) Universidade Federal de Itajubá (UNIFEI- ITABIRA); Departamento de Engenharia Mecânica
}

ABSTRACT: In the last decades, its noticed that the high technological growth is driven by the industries that, in order to survive in the market, are forced to work always with ideal parameters and seek the optimization of their processes, being that in the area of welding, this has been occurring always in the direction of cost reduction. Therefore, this work has as objective to study the effect of welding operating conditions on the geometry and contact angle of a welded joint with self-protected tubular wire. The process with tubular wire has been growing due to its formation of cord with high quality, good visual aspect and to be used in all welding positions, through appropriate adjustments of its operational parameters. Thus, during the experiments, the voltage, current, contact part nozzle distance and wire feed velocity were varied. The data were submitted to statistical analyzes using commercial MINITAB-14 software. The results indicated that the best regulation of the welding parameters are essential for the optimization of the geometric characteristics of the bead. The increase of the nozzle part contact distance caused the reinforcement to decrease and an increase in penetration occurs, this condition being considered optimal for a weld bead.

KEYWORDS: Welding, Self-Protected Tubular Wire, Geometry, Contact Angle. 